\title{
Plasticidad de las formas o cartografías del deseo. Una lectura de La mujer desnuda de Armonía Somers
}

\author{
NATALIA LORIO Universidad Nacional de Córdoba, Argentina / natilorio@gmail.com
}

\section{Resumen}

Nos interesa en este texto plantear una lectura de $L a$ mujer desnuda de Armonía Somers desde un materialismo del deseo. Para ello no solo postulamos una suerte de cartografía del deseo (entendido como revelación de un vacío, esencialmente distinto de la realidad estática y dada, es decir, como inquietud y negación), sino que también apostamos por su puesta en relación con una forma de materialidad (desde la propuesta de plasticidad de Malabou) donde el cuerpo, el contacto y el contagio son asumidos desde un materialismo donde la forma no coincide con su presencia. El materialismo que está puesto en juego en esta nouvelle de Somers (¿un materialismo erótico?) permite, por un lado reconocer en su personaje al deseo mismo (sin objeto, deseo de deseo) y, por otro, cartografiar en sus movimientos, la plasticidad de las formas que se juegan como la apertura a la forma del otro en sí mismo: convertibilidad de la forma y el deseo in-humanos para ir más allá de la noción de comunidad, pensando en esas formas y experiencias que se dan entre la soledad y la comunidad, entre la muchedumbre y la singularidad.

Palabras clave: materialismo / deseo / inhumanidad / común / plasticidad
Plasticity of the forms or cartographies of desire. A reading of Armonía Somers's La mujer Desnuda Abstract

In this text we propose a reading of La mujer desnuda of Armonía Somers from a materialism of desire. We do not only postulate a kind of cartography of desire (understood as a revelation of a vacuum, essentially different from the static reality), we also propose on its connection with a form of materiality (from Malabou's plasticity concept) where body, contact and contagion are assumed from a materialism where the form does not coincide with its presence. The materialism that we find in this nouvelle of Somers (an erotic materialism?) allows, on the one hand, to recognize in his character the desire itself (without an object, desire for desire) and, on the other, to map in his movements, the plasticity of the forms that are played as the opening to the form of the other in itself: convertibility of the in-human form and desire to go beyond the notion of community (hinking of those forms and experiences that occur between the loneliness and the community, between the crowd and the singularity).

Key words: materialism / desire / inhumanity / common / plasticity

Recibido: 1/3/2020. Aceptado: 9/4/2020

Para citar este artículo: Lorio, N. (2020). Plasticidad de las formas o cartografías del deseo. Una lectura de La mujer desnuda de Armonía Somers. El taco en la brea, 11 (diciembre-mayo), 143-152. Santa Fe, Argentina: UNL. DOI: 10.14409/tb.v1i11.9163 
Escribir no es ciertamente imponer una forma (de expresión) a la materia vivida (...) Escribir es un asunto de devenir, siempre inacabado, siempre en vías de hacerse, y que desborda toda materia vivible o vivida. Gilles Deleuze, La literatura y la vida.

La palabra deseo porta para el pensamiento un carácter maldito, adjudicable por cierto a que echa por tierra aquellos caracteres que es posible conceder a algo que se pretende estable, un sustrato o una sustancia. El deseo revela el movimiento, inquietud del ser, su impureza. De allí su incomodidad. Se liga asimismo a la posibilidad de salir de sí y desde allí, a lo que pone en relación: con las cosas, con otros y otras, pero también con la singularidad y la soledad, así como con la mímesis y la conformación de un común. Tan vasto territorio que aúna la singularidad y lo común, la soledad y la comunicación se materializa en las formas que se ligan al deseo entendido como revelación de un vacío, esencialmente distinto de la realidad estática y dada, es decir, como inquietud y negación.

En este sentido, nos proponemos pensar el deseo fuera o más allá de una economía del ser (que excluye lo disruptivo). Desde este marco leemos La mujer desnuda de Armonía Somers, para ir más allá de la noción de comunidad, pensando en esas formas y experiencias que se dan entre la soledad y la comunidad (Alemán), la muchedumbre y la singularidad (Malabou). La nouvelle de Somers aquí es motor y la excusa para ligar lo común con el deseo. En una suerte de materialismo' (¿un materialismo erótico?) que tiene como eje la propuesta de Malabou respecto a la plasticidad de las formas, donde la forma no coincide con su presencia, las formas de lo común allí presentes se juegan como la apertura a la forma del otro en sí mismo. Dinámica del encuentro, la conjugación, conflicto y convertibilidad de la forma de la soledad en la intimidad y su metamorfosis en lo común.

\section{Materia deseante}

En el relato se da la aventura de una mujer y las formas de contacto y contagio. No cualquier mujer. No cualquier contacto, menos aun cualquier contagio. Lo que se contagia es el $\mathrm{mal}^{2}$ de las formas que se desvanecen. El mal incrustado aquí supone la posibilidad de atravesar los cierres e identidades, o si se quiere, la identidad como cierre. ${ }^{3}$

La mujer desnuda comienza relatando la salida: de una casa, de una propiedad —aunque recientemente adquirida — sin límites claros. Sale tras un ritual de años cumplidos. Un tren la lleva a esa casa, rodeada de bosque y de noche. Pero no solo el espacio es el atravesado: también las identidades y semejanzas, las distancias de las formas y los lugares de lo ya conocido. En el mapa que presenta Somers, no importan tanto los lugares como las formas: como una cartógrafa de espacios fabulados o imaginarios, desconocidos aún, a veces sospechado a veces sospechoso, se traza un mapa de movimientos más que una cuadrícula estática. En dicho mapa — como en los mapas de antaño—, se perfilan también los seres que habitan el lugar, que hacen el lugar. En ese retrato, incluso las diferencias entre géneros y especies se encuentran transfiguradas, el reino vegetal en la nocturna experiencia de esta mujer aparece como un animal, incluso el medio de uno y otro, aparecen, en su plasticidad:

Sí, realmente, el bosque le parecería desde el principio un cetáceo varado. En un solo día de viento en que le fuera dado verlo, le habían conocido en la locura, una especie de rabia impotente como la de ciertas formas ancladas de rebelión humana. Se movía sin abandonar el sitio, resoplaba enviando ráfagas cargadas de su ruido. Pero no más allá del propio espectáculo de esclavo amotinado. Luego volvía a quedar inmóvil por un tiempo, apenas si con la incontenible respiración de su masa. (Somers:16) 
Pero las formas no son fijas, las formas se metamorfosean. Como sostiene Deleuze, «devenir no es alcanzar una forma (identificación, imitación, Mímesis), sino encontrar la zona de cercanía, de indiscernibilidad o de indiferenciación de tal modo que ya no pueda distinguirse de una mujer, de una animal o de una molécula» (2006:13-14). La rebelión de las formas no solo es rebelión humana, participan de cierto estallido y transfiguración otros seres, otras formas (no sin dejar de señalar el momento estático-esclavizante y el momento de amotinamiento, la dinámica del movimiento deseante). Y así como la mujer llega en soledad a esa casa gracias a la evasión que le posibilita el tren, cortando el campo y «despojada de todo vínculo anterior», así también comienza la aventura de su metamorfosis y la de su percepción, aquella en la que va a tensar su soledad con lo que abre un espacio de lo común en la intimidad. ${ }^{4}$ Vale aclarar que se trata de una intimidad rara, díscola, acaso in-humana, ${ }^{5}$ que permite conformar otros territorios de lo sensible, otros movimientos de la materia, modos diversos de relaciones con los otros seres, incluso los no-humanos.

En este sentido, huelga decir que el relato tramado desde la materialidad organiza todas las experiencias desde las experiencias del cuerpo, de un cuerpo de mujer al desnudo. Acciones, modos de sentir y movimiento. Pero, claro, el cuerpo no es el sujeto y por ende, quien protagoniza esta historia no es un sujeto de la experiencia en sentido filosófico (ni del racionalismo cartesiano ni del idealismo hegeliano). Es una mujer desnuda que habita el mundo desde su cuerpo, estando en el mundo sin mediaciones materiales-culturales (es decir, sin los velos del pudor y sin vergüenza de ser un cuerpo), percibiendo(se) en contacto $y$ a distancia de otros cuerpos, expuesta (tanto al tacto como al rasguño, a la mirada como a la conspiración).

Hasta que ocurrió la nueva aventura: el bosque. Rebeca Linke tuvo un minuto de pasmo. Los árboles le habían nacido de golpe, apretados, negros y con un cuchicheo que se hizo como la suma de todos los alientos sobre su rostro. Los eludió cuanto pudo. Habiendo marchado hasta ese momento en diagonal, logró encontrarse así en la ruta mezclada de arena y hojas que separaba el bosque del río. Percibió con alivio su blandura, y ya hubiese querido tenderse un instante allí, donde le era posible completar el cielo sin necesitarlo. Pero le pareció, de pronto, que el bosque la había identificado, que la estaba espiando. Porque se acostumbrase ella al secreto de la masa, o porque en realidad ésta hubiera callado, lo cierto fue que la envolvió de repente en un silencio brutal, esa mudez de conspiración en muchedumbre. (Somers:23)

El mundo que la rodea está atravesado por la volición, por el deseo. El deseo no es solo humano. Desde este materialismo poshumano, o mejor, inhumano, el deseo atraviesa las diferentes formas de vida, no es un carácter exclusivo de la humanidad, sino que podría decirse que cada modo de vida podrá hacer con el deseo según su estructura, según sus condiciones. En un momento de temor frente a ese bosque que conspira contra ella, ella se convence:

«Soy tan real como ellos —-murmuró para calmarse— solo que más positiva. Puedo escabullírmeles, burlarme de sus pies enterrados...»

Nada, ni siquiera uno que se arrancase de sí en un desplante individualista. Apretó el paso en la arena. Pronto su nuevo ritmo se transformó en una alocada carrera a la grupa del bosque, que duró lo que los árboles se propusieron, parados sobre su única pierna como una procesión de lisiados. (23-24) 
La transfiguración no es del mundo, sino de la perspectiva: al desnudo, a una sensibilidad desnuda el mundo se le aparece distinto, su materialidad es distinta, tan atravesada por la volición y la rebelión de las formas como por sus condicionamientos. ¿Cómo no pensar desde allí la posibilidad de un materialismo insumiso, un materialismo interpretativo que vuelve difícil las taxonomías? Este materialismo insta a traspasar el umbral antropocéntrico hacia lo no-humano (inhumano?) en-la-figura-de-la-mujer-desnuda, jugando en esa misma partida a traspasar lo ideal de las formas (asumidas como) nobles hacia los fenómenos brutos, lo monstruoso por excesivo. En este materialismo las palabras solo permiten capturar en las cosas los caracteres que determinan una situación relativa, pero todo está atravesado por el matiz del deseo, aspecto que introduce los valores decisivos de las cosas y los seres (no en su identidad estática, sino en su movimiento).

En este sentido, se trata de un materialismo no mecanicista, no humanista, insumiso al antropocentrismo. ${ }^{6}$ Georges Bataille ${ }^{7}$ propuso en los años 30 (en la revista Documents) la idea de un bajo materialismo (1991:7) que recuperaba el valor del inconsciente y que reconocía los desplazamientos de la carga simbólica y libidinal que atraviesa la materia (nunca pura). Este materialismo bajo representaba la rebelión contra el idealismo, abogaba por la insumisión a cualquier autoridad, idea o sujeto, incluso a cualquier forma humana —acaso por ello Bataille vuelve su mirada sobre las figuras gnósticas de arcontes con cabeza animal一, «la materia baja es exterior y extraña a las aspiraciones humanas ideales derivadas de tales aspiraciones [de un valor superior]» (7). También en esta novela los elementos de la naturaleza y los seres están atravesados pero la insumisión a la identidad de las formas: la mujer desnuda ve en el bosque la grupa, la muchedumbre de árboles son las ancas de un caballo o yegua, ve en cada árbol un caballo con su única pierna y se dice a sí misma: «Quizás las cosas estén buscando los orígenes» (Somers:24), un origen caótico, de mezcla, hibridación y caos. Un origen inquieto y deseante que burbujea aún:

Visto aparecer así, de golpe, el río le sugirió algo más de lo que emanaba de la definición corriente. Un largo ser vital acostado sobre su espalda, y sobrellevando eso tan solitariamente indescifrable que disuelve su médula (...) Pues en tanto ella avanzaba como a puntas de compás hacia un lugar sin nombre, el río la seguía cada vez menos olvidado de sí, menos casto y desentendido que en el primer momento. (33)

\section{Mujer acéfala}

La plasticidad enuncia el sentido más sensible, lo vivo, de la subjetividad, la relación que esta última trama con el acontecimiento.

Catherine Malabou, La plasticidad en espera

Ella ha salido desnuda. Un abrigo la cubre, pero está desnuda. En ese lugar elegido, en la casa del bosque, hay un libro que tiene adentro una daga. Esa daga es la que le va a demostrar que ella sí sabe hacerlo: sabe atravesar formas, cortar arterias, cortar su cuello, hacer rodar su cabeza. «La cabeza rodó pesadamente como un fruto» (Somers:19). Allí comienza a acaecer su nuevo (otro) estado, «Al tocar la garganta se terminaban las preguntas» (18), estado en que ya no puede dejar de tener en cuenta su propia materialidad, su cuerpo.

Si puede decirse que su estado anterior era el de ser un sujeto (mujer) que puede olvidar su cuerpo o mantenerlo amarrado a la cabeza (logos, yo, arché, principio), su nuevo estado es más 
bien el desasimiento de ese principio. El sujeto como estructura «de la sustancia o del substrato, del hypokeimenon, con sus cualidades de estancia o de estabilidad, de presencia permanente, de mantenimiento en la relación a sí, aquello que enlaza al "sujeto" a la conciencia, a la humanidad, a la historia... y sobre todo a la ley» (Derrida:155) es lo que ya no tiene retorno. No tiene retorno porque el sujeto (también) es una fábula (lo que no quiere decir que no haya tenido sus efectos, o que no haya aquí o allí «efectos de subjetividad»), que es preciso desimplificar, deshomogeneizar en tanto fábula (Derrida).

Frente a la primacía de la razón, de la cabeza, del primado de la ley, la caída de esta estructura (de esta architectura), no hace sino recordar la ficción, la fricción de esa unidad y de la autorepresentación: si bien la mujer vuelve a «montar» la cabeza sobre su cuello, el quiebre y el plegado están allí patentes. Un pliegue, que no es ni resumen ni identificación (Didi-Huberman:56), es más bien un ejercicio de deshomogeneizar un modo de ser. Dejar de ser sujeto de la experiencia para ser la mujer (desnuda) que hace experiencia: de su pliegue cabeza/cuerpo, de sus límites y potencias, de su libertad.

Del órgano perdido a la evidencia de la imposibilidad de su retorno. Pliegue. La cabeza aquí no es solo un órgano, es la metáfora de la unidad supuesta, de la jerarquía que estructura un quien, de la elevación sobre el cuerpo y la materia. La mujer acéfala yace en el piso, como una blemia femenina (iqué escándalo!)... y sin embargo, el hormigueo de «las más elementales voliciones» vuelven a reunir esos dos elementos heterogéneos, contradictorios, «pero Rebeca Linke ya no reincidiría en el antiguo apareamiento de las dos mitades contradictorias de sí misma» (Somers:20). Es un pañuelo el que frena y cubre la lluvia incontrolable de la sangre que cae de su cuello.

La cabeza cortada y plegada, el cuerpo desnudo (con todos sus pliegues), una estructura que rompe su estructura interna y se expone en su herida, desde su herida y en su exposición. Como en el psicoanálisis lacaniano, donde es en la afanisis que aparece el sujeto (Lacan:11), la protagonista de esta historia (Rebeca, Eva, Gradiva, la madonna como la llama el cura, Friné el nombre que ella se inventa para sí y su amante) se manifiesta en ese movimiento (en ese fading del sujeto): la desaparición que se puede calificar de letal es la que la hace ser. En esa caída aparece la mostración del cuerpo en su privilegio, en la caída aparece la posibilidad de enunciarse en su devenir desnudo. Hay un quien tachado, borrado, herido. O mejor, herido su quien y desde allí alucinado, inventado, ella es la materia del cuerpo antes que la cabeza (arche, principio, etc.), ella es la invocación de la extrañeza de esta materia deseante (rebelde, insurrecta, poética, sensible, acaso sombra delicada del pecado). Una blemia tras su metamorfosis, extranjera y extraña, inaudita. Blemia que rompe con la antropomorfización regida por lo elevado, por la cabeza.

Si seguimos los rastros de Bataille en su escrito de 1930, «El bajo materialismo y la gnosis», podemos insistir sobre la arbitrariedad que sostiene el estigma metafísico que asume como consecuencia una abstracción sistemática, donde la materia aparece relegada y cuando aparece es cubierta por el manto de lo abstracto. Desencadenar la materia de su yugo y proponer un materialismo de lo bajo es, en definitiva, hacer lugar a lo que hay de monstruoso y obsceno en la materia. Recuperar el carácter maldito constitutivo de la materia, es el modo de afirmar las fuerzas y agitaciones que están obrando en la misma. Como en una representación gnóstica, esta mujer sin cabeza es el índice y el factor para señalar una figuración del mundo en la que la materia misma se muestra en su contradicción, en la que no deja de destellar una suerte de materialismo insumiso: la materia como un principio activo eterno y autónomo del mal, el mal irreductible al principio moral y motor de la creación (Bataille, 1991:7). 
En este materialismo del deseo — como en el deseo— importan los desplazamientos, importa dar cuenta de lo que no dura y de la perturbación de las formas. De alguna manera se opera mancillando lo aceptable: a la elevación del espíritu y las grandes ideas de justicia y rectitud o a la simple siembra de la rutina que idealiza lo estático, esta mujer inyecta la perturbación, la contaminación de espacios y figuras. Es la materia la que se insubordina a quedar presa en la cárcel burocrática de la separación y jerarquización de la cabeza y las proporciones, de las expectativas de seguridad de la rutina.

Aunque vuelve a montar su cabeza en ese cuerpo ahora rector, volver a ponerse la cabeza no implica volver al estado anterior. Si, como sostiene Nancy (2014) —respecto a lo encantadoramente problemático de la cuestión del sujeto en Hegel en tanto «lo que es capaz de retener en sí su propia contradicción»— el carácter del sujeto siempre está atravesado por el extrañamiento que se hace propio, aquí no se trataría de volver a la subjetividad como una sustancia. Se trata más bien de reconocer con Malabou que la subjetividad nunca es pasiva, menos aún instancia fija y sólida, «sino una instancia plástica. En cierto sentido, ella efectivamente recibe sus predicados, recibe su forma, como una cera, como una bola de greda: ella es esto, esto y también después es aquello...» (Malabou:91). Como advierte Malabou respecto al sentido de la plasticidad, no hay vuelta atrás, ni pasividad, antes bien hay un voto de porvenir, con lo que le sucede.

En este sentido, la forma ya ha sido mancillada, la forma ha cambiado en una metamorfosis vital que no solo impacta en su forma-cuerpo, sino en su forma-visión, en su forma-moral. «Era, además, difícil y molesto volver al mundo por los ojos, especie de desván donde las cosas y sus imágenes parecían reivindicar por la fuerza de la costumbre su derecho al sitio normal, arañando sin compasión la inocencia del aire» casi como un injerto vegetal, dos savias que se trenzan de nuevo. No importa ya la herida por lo que quema, sino como marca de ese otro estado «su vigilia retomada bajo nuevas formas» (Somers:21).

\section{Las formas de lo común}

Los amantes exponen por excelencia la inoperancia de la comunidad. La inoperancia es la faz común y la intimidad. Pero la exponen a la comunidad que ya reparte la intimidad de estos seres. Están para la comunidad sobre su límite, están afuera y adentro (...) Recíprocamente, en su amor mismo, es la comunidad quien les presenta sus singularidades, sus nacimientos y sus muertes.

Jean-Luc Nancy, La comunidad inoperante

Comienza la noche de la mujer, la primera noche de la mujer. Ya no tiene a qué aferrarse. Las estrellas demasiado lejos, la casa ya está atrás, las zarzas que la lastiman. Vuelve sus manos sobre su cuerpo en «experiencias de inventario minúsculo, pero capaces de sustituir el viejo miedo por un desacatamiento absoluto de sus riesgos». Su mirada y sus pasos trazan diagonales, desmarcan rumbos, «dejó su vida personal atrás, sobre una rara frontera sin memoria» (Somers:23). De una frontera a otra, de su casa al bosque, del bosque a otra casa que no es la suya. En la casa otros cuerpos - con sus respectivas cabezas- que duermen y sueñan sin soñar. La mujer desnuda-de-nombre conmueve el espacio de los otros, el espacio de sus sueños y deseos. Conmueve las formas de los lazos, descubre para ellos que lo común no es una propiedad sino un vacío, una nada. La plasticidad de las formas no solo involucra, por tanto, su subjetividad, también involucra las formas de lo común. 
Si bien su llegada a la casa (y luego al pueblo) no es estrepitosa ni exhibicionista, más aun se podría decir que llega a entrar en contacto de forma sigilosa y delicada casi como un contagio imperceptible pero contagio al fin. Pero, ¿qué es lo que inocula?, ¿qué contagia? La plasticidad de su forma de mujer, la potencia de su libertad deseante, la herida de su subjetividad (o su subjetividad como herida y pliegue). Contagia el deseo (y no necesariamente el placer). Es decir: contagio de deseo del que no se sale indemne. No es inocuo el contacto:

Ven, toca, estoy desnuda. Tomé mi libertad y salí. He dejado los códigos atrás, las zarzas me arañaron por eso. El bosque me lanzó el aliento a la cara, la serpiente quiso volver a intentar la sucia historia de la fruta. Eran las mismas cosas de antes, de cuando yo les pertenecía. (Somers:27)

La mujer irrumpe en la vida del leñador y de la leñadora. Pero su deseo, como todo deseo, es siempre deseo de otro. Interesa en este punto dar cuenta de algunos matices del deseo: ante la idea de que el deseo humano es infinito, Lacan afirma la función más bien limitada del deseo en tanto que «El deseo más que cualquier otro punto de alcance humano, encuentra en alguna parte su límite» (39). A diferencia del placer que fija los límites del alcance humano y que se rige por el principio de homeostasis en la regulación de la libido (en una dinámica de acumulación y liberación), el deseo transgrede pero es límite, franquea el principio de placer, pero a la vez está limitado. El deseo es deseo del otro, pero no hay respuesta directa al deseo, y así como no hay lo común como sustancia, no hay cierre... hay siempre deslizamientos. Hay lo que no encaja.

Así, en La mujer desnuda, lo que recorre los territorios moviendo las trazas habituales de los seres humanos y no-humanos es el elemento de deseo des-cubierto, desnudado en la materia. Las formas en movimiento no solo involucran a la mujer y al leñador que están conmovidos por su encuentro, sino que se dan ondas expansivas, ondas de contagio que mueven las aparentes propiedades y seguridades antes arraigadas. El movimiento, el temblor que describe Somers es el que se da de la crisis de la unidad indivisible (sea el cuerpo de la mujer, sea el cuerpo social) coherente y autoconsciente, fundamento de toda representación y orden racional, a su alienación fundante, su precariedad y desgarro constitutivo.

En el deseo desencadenado se desmoronan las formas de lo común y de la intimidad que se representan como una propiedad, como algo que se tiene y se posee: el leñador que la desea y mancilla a su compañera de lecho buscando a la que ya no está. El leñador buscando a Eva-JudithGradiva, transformándose en un animal de caza. La población en estado de alarma. El amoralismo que va corroyendo las formas estáticas-en-movimiento, devorándolas como un ácido. El cura «Vio, efectivamente, desde el principio que el pueblo había despertado ese domingo con un estilo que no era el propio. Tal si hubiera cambiado de pellejo o mudado de aire» (Somers:57). Y quiere curar la enfermedad que está gozando él mismo (tanto como le teme) y da un largo discurso gritando que ella no era real «sino una sombra del pecado, algo así como el pecado de nosotros... que acababa de tomar tus formas» (93).

Cuáles son las formas estáticas-en-movimiento: la población, las personas, la vida familiar, la seguridad del quehacer del trabajo sin deseo manifiesto ni encubierto. El cura que dice no poder y que se contagia, luego con la furia de las imágenes, los colores y movimientos de la pintura y los lienzos. Desde siempre el deseo. Aquí tensando el nervio que recorre el sentido y lo sensible entre la muchedumbre y la singularidad, ese entre que Malabou señala en tanto proceso de metamorfosis, 
proceso que levanta la prohibición del contacto con lo otro al mismo tiempo que reconoce tal prohibición (24). Pero el deseo puede configurar una población en su gestión de días tras días, reproducción, trabajo, sermones, reglas y códigos; estructuras familiares, deducción de la rutina de las formas. O puede emerger como máquina o monstruosidad deformadora de toda forma previa:

Odiaban a la desconocida, se odiaban a ellos y entre ellos. Por culpa de la mujer se habían descubierto cada uno a sí mismo, y esa revelación es de las que no se perdonan, al menos cuando hay algo más que tierra bajo la piedra. Ella era libre para su propio desnudo, en eso no iban a surgir discusiones. Pero la libertad individual del acto en sí arrastraba a cada uno a pensar en la imposibilidad de la suya. (Somers:77)

Un mapa, una cartografía se va trazando en este recorrido que avanza desde el deseo. Es decir, desde lo que se supone una propiedad (casa, cuerpo, pueblo) a lo impropio del cuerpo, comunidad, bosque, el río, lo inhumano... una cartografía que, desde este materialismo de lo insumiso supone captar en las formas su potencial plasticidad atravesadas por dos modos del tiempo entrevisto por el psicoanálisis lacaniano: entre la forma de la duración (de las cosas y sujetos) y el deseo cuya estructura es más bien la de pulsación de una ranura, una aparición evanescente (Lacan:40).

Ella, y en ella el deseo, aparece como contaminación, como lo que llega para señalar lo que es un límite para conocerlo, franquearlo. Pero también para señalar un terreno ávido de experiencias en y desde la soledad en común (Alemán), y el común que es el encuentro de soledades en la intimidad que no puede sino ser trágica. ${ }^{8}$ Como señala Nancy a partir de Bataille, no hay sociedad entre los amantes, hay más bien comunicación —en lo inaccesible de su propia comunidad y de otra comunidad (Nancy, 2000:68) — . Pero la forma de lo común entre los amantes está atravesada también por esa temporalidad de la pulsación... Un cuerpo que yace tendido y la frágil duración de esa nada en común.

En el deseo que acarrea lo que sustenta de una imagen del pasado hacia un futuro evanescente, indestructible y a la vez inconsistente, está expuesta la apertura de las formas, la insumisión de la materia, las otras/nuevas cartografías que pueden trazarse, siempre inacabadas, plásticas. Pero, acaso no sea en vano señalar que el desquicio de las formas de lo común y su plasticidad son desencadenadas en la obra de Somers que hemos considerado por una mujer. Que quien pliegue esos cortes, esos movimientos, incluso despliegue otras coreografías en el espacio común sea una mujer no es un dato menor. No es un detalle olvidable, toda vez (jo cada vez!) que lo que se expone, en su límite, es la potencia tan política como ética que no cesa de mostrar que, para la mujer, ${ }^{9}$ «Desear significa participar en el derecho a desear» (Butler:285).

\section{Notas}

1 El cuerpo es el elemento, los afectos un «condensado apretado, ceñido de experiencias vividas pasadas, porque cuando lo sentimos y queremos decirlo aviva en sordina la epifanía primera que le sigue dando el matiz de su origen» (Rozitchner:18). En el materialismo ensoñado que propone Rozitchner, el deseo que aparece también con/en la castración, atravesado por la falta (aunque asumiendo otra encarnadura respecto al tratamiento lacaniano).

2 La noción de mal que aquí retomamos es la desarrollada en gran parte por la literatura y filosofía maldita, específica- 
mente por Georges Bataille, que reconoce en el mal un principio ontológico que permite a los seres salir de su aislamiento y ponerse en juego. En este sentido, el mal y la transgresión al bien (como principio de identidad y cierre inmunitario de los seres) son las vías para ir más allá de la perduración y cerrazón de los seres (sean estos considerados sujetos individuales como sujeto colectivo). Cf. (Bataille, 1972:48-66).

3 Huelga decir que esta nouvelle publicada en 1950 llega en nuestro presente mostrando con certera actualidad el contagio del mal que se da en la puesta en cuestión de la «identidad» de la mujer, de lo femenino y el trastocamiento contagioso de otras «identidades» y construcciones identitarias que hoy sacuden la política, los debates culturales y los posicionamientos éticos y estéticos. En este sentido, señalo de modo ejemplar el trabajo de Alejandra Castillo, específicamente Ars Disyecta, donde la autora traza formas y figuras de lo que llama una corpo-política a partir de prácticas estéticas que cuestionan «el signo masculino/femenino a través de la transgresión, la denegación o la incorporación paródica» (12).

4 Interesa aquí retomar el trazado de lo íntimo que plantea Phillippe Jullien en tanto se trata de una experiencia de cercanía no espectacular ni escandalosa, sino acaso silenciosa que remite a un adentro compartido, a una experiencia de lo interior del estar cerca.

5 Si bien inhumano puede tomarse como la posibilidad en lo humano de la sumisión a las formas de negación del otro o de sí mismo, quisiéramos aclarar que el sentido de lo in-humano que aquí traemos refiere más bien a la posibilidad de un devenir no-humano, no antropomórfico, más bien —siguiendo a Deleuze y Guatari- abierto a los pliegues y despliegues de la materia y sus formas. Si lo humano se teje en clara vinculación con el movimiento cultural de la Ilustración y su programa filosófico-político, lo in-humano puede pensarse acaso en términos de nuevas cartografías sensibles del deseo donde es recuperada la alteridad de los cuerpos (sean humanos o no) y la materia. Resulta importante recordar que Rosi Braidotti no deja de señalar el amplio consenso del que disfruta el término «humano», que «conserva la tranquilizadora familiaridad del lugar común» (9), mostrando la construcción ético-político-estética de dicho terreno o propiedad supuestamente adquirida, asumida y asegurada. Frente al apego a la especie humana como si se tratara de un dato de hecho, Braidotti propone otra cartografía de lo poshumano desde una alternativa materialista, secular, fundamentada y no sentimental para afrontar la mercantilización de la vida que caracteriza al capitalismo avanzado. Lo poshumano aparece en Braidotti como la extensión de lo humano, atravesado por las contradicciones y los conflictos sociales del mundo contemporáneo.

A distancia de la autora, nos interesa aquí (y respecto a la lectura que proponemos de La mujer desnuda) recuperar el sentido sentimental, estético y sensible de lo in-humano que sospechamos en la propuesta de Somers: a diferencia del poshumanismo acaso sea en nuestro caso más ajustado hablar de inhumanismo en tanto no hay un quien que articule los caracteres de lo humano, sino un lugar, un espacio que posibilita otros contactos y márgenes (incluso con la humanidad) (cf. Cragnolini, 2009, 2017). En esta vía nos ha resultado valioso el desarrollo sobre la animalidad y lo inhumano en Kafka llevados a cabo por Evelyn Galiazo que, retomando a Deleuze y Guattari, sitúa la propuesta de lo inhumano en sus dos frentes posibles «en los relatos de Kafka el animal funciona como desterritorialización que libera a la materia expresiva de los diversos aparatos de captura antropológica. No obstante, dado que lo humano y lo inhumano no son en realidad dos entidades opuestas separadas sino dos vectores en el campo de fuerzas de lo viviente, la narrativa kafkiana parece dar cuenta, al mismo tiempo, de que operando como línea de fuga, el animal también puede condensar en sí mismo esas fuerzas coercitivas que se coagulan y cristalizan negativamente» (Galiazo:133).

6 Para un desarrollo más amplio sobre la propuesta de este tema, remitimos al tratamiento que llevamos a cabo sobre el materialismo insumiso en torno a Documents (Lorio), pero ampliable a otros abordajes y propuestas estéticas.

7 Bajo la lógica del inconsciente, Bataille señala los múltiples desplazamientos que hacen aceptables los objetos del deseo (del órgano a la persona, de los estambres y pistilos a los pétalos que los rodean). Lo que consideramos bello de las flores está adecuado a lo que debe ser, al ideal humano. Sin embargo, las flores también se marchitan, se debilitan, se vuelven pútridas y solo queda de ellas un hedor que acrecentará la basura.

8 Para ampliar la idea de una comunidad de los amantes remitimos al libro de Jean-Luc Nancy, La comunidad inoperante y también de Maurice Blanchot La comunidad inconfesable. En ambos textos se trama el problema de la comunidad en Bataille y su destino trágico, en tanto no hay fusión posible que no sea trágica, ni hay más que soledades que se abisman en su límite y desde allí comunican su imposibilidad en el instante. 
9 Acaso valga la pena recordar que en Sujetos del deseo de Judith Butler se prefiguran algunos elementos que continúan profundizando en desarrollos teóricos posteriores y otros se abren desde algunas discusiones o tensiones con los autores que ella retoma (Kojève, Foucault, Deleuze, Lacan, entre otros). Específicamente respecto al tratamiento del deseo en Lacan es que Butler deja de hablar de «sujeto» en términos generales y distingue la relación del hombre y de la mujer respecto al deseo, señalando —en la interpretación lacaniana- la relación de privilegio del hombre respecto al objeto del deseo y la negación respecto al objeto del deseo en el caso de la mujer. De allí, retomamos el gesto de Butler que permite inscribir el deseo con relación al género, con relación a la mujer como quien al desear ya está poniendo en juego la posibilidad de jugar ese juego: participar del derecho a desear.

\section{Referencias bibliográficas}

Alemán, J. (2012). Soledad: común. Políticas en Lacan. Buenos Aires: Capital intelectual.

Bataille, G. (1972). Sobre Nietzsche. Madrid: Taurus.

(1991). Le bas matérialisme et la gnose. En Hollier, D. (Comp.). Documents. Paris: Jean-Michel Place, 1-8.

Blanchot, M. (1999). La comunidad inconfesable. Madrid: Arena.

Braidotti, R. (2015). Lo posthumano. Madrid: Gedisa.

Butler, J. (2011). Sujetos del deseo. Reflexiones hegelianas en la Francia del siglo XX. Buenos Aires: Amorrortu.

Castillo, A. (2018). Ars disyecta. Figuras para una Corpo-política. Santiago de Chile: Palinodia.

Cragnolini, M. (2009). Extrañas comunidades. La impronta nietzscheana en el debate contemporáneo. Buenos Aires: La Cebra.

(2017). Comunidades animales en la obra de Kafka. En Ruiz Gutiérrez, A.M. et al. Franz Kafka: culpa, ley y soberanía. Medellín: UPB, 181-194.

Deleuze, G. (2006). La literatura y la vida. Córdoba: Alción.

Deleuze, G. y Guattari, F. (1978). Kafka. Por una literatura menor. México: Era.

Derrida, J. (2005). «Hay que comer» o el cálculo del sujeto. Entrevistado por Jean-Luc Nancy. Confines, (17), 151-171.

Didi-Huberman, G. (2018). Notas sobre antromorfismo en Documents. En Colectiva Materia [Coord.]. Indisciplina: estética política y ontología en la revista Documents. Buenos Aires: RAGIF Ediciones.

Esposito, R. (2003). Communitas. Origen y destino de la comunidad. Buenos Aires: Amorrortu.

Galiazo, E. (2010). Patas arriba. Lenguaje, animalidad y animalización en los cuentos de Kafka. En Kaminsky, G. et. al. Kafka: preindividual, impersonal, biopolítico. Buenos Aires: La cebra, 51-71.

Jullien, Ph. (2016). Lo íntimo. Lejos del ruidoso amor. Buenos Aires: El cuenco de plata.

Lacan, J. (2006). Los cuatro conceptos fundamentales del psicoanálisis. Buenos Aires: Paidós.

Lorio, N. (2018). Documentos de fuego y polvo (prólogo). Colectiva Materia [Coord.]. Indisciplina: estética política y ontología en la revista Documents. Buenos Aires: RAGIF Ediciones.

Malabou, C. (2010). La plasticidad en espera. Santiago: Palinodia.

Nancy, J-L. (2000). La comunidad inoperante. Santiago de Chile: Arcis.

- (2014). ¿Quién viene después del sujeto? Política común, 6. http://dx.doi.org/10.3998/ pc.12322227.0006.002

Somers, A. (2009). La mujer desnuda. Buenos Aires: El cuenco de plata.

Rozitchner, L. (2011). Materialismo ensoñado. Buenos Aires: Tinta Limón. 